\title{
Challenges of ERAU's First Suborbital Flight Aboard Blue Origin's New Shepard M7 for the Cell Research Experiment In Microgravity (CRExIM)
}

\author{
Pedro J. Llanos ${ }^{1}$, Kristina Andrijauskaite², Vijay V. Duraisamy³ ${ }^{3}$ Francisco Pastrana ${ }^{4}$, Erik L. Seedhouse ${ }^{1}$, Sathya Gangadharan ${ }^{3}$, \\ Leonid Bunegin ${ }^{5}$, Mariel Rico ${ }^{6}$ \\ ${ }^{1}$ Department of Applied Aviation Sciences , Embry-Riddle Aeronautical University (ERAU), Daytona Beach, FL; '2Department of Molecular \\ Medicine, University of Texas Health Science Center (UTHSCSA), San Antonio, TX; ${ }^{3}$ Department of Mechanical Engineering, ERAU, Daytona \\ Beach, FL; : ${ }^{4}$ epartment of Aerospace Engineering, ERAU, Daytona Beach, FL; ${ }^{5}$ Department of Anesthesiology, UTHSCSA, San Antonio, TX; \\ ${ }^{6}$ NanoRacks, Internal Pressurized Payloads, Houston, TX
}

Abstract

Cell Research Experiment In Microgravity (CRExIM) was launched aboard Blue Origin's New Shepard suborbital vehicle on Tuesday, December 12, 2017, from the West Texas Launch Site in Van Horn, Texas. One of the aims of this science experiment was to assess the effects of microgravity on murine T-cells during suborbital flight. These cells were placed in a NanoLab with a data logger that sensed the acceleration, temperature, and relative humidity during preflight, flight, and postflight operations. Some discrepancies in sensor measurement were noticed, and these errors were attributed partly to the difference in sampling rates and partly to the different locations of the sensors, which made it difficult to obtain highly accurate measurements of the accelerations and to correlate both sets of data. This paper discusses the setbacks and lessons learned, which made our team find new alternatives while meeting all milestones as mandated by NanoRacks and Blue Origin. This manuscript highlights these alternatives that led to the success of the mission and gives recommendations that will enable customers to alleviate some of these challenges in future flights.

Keywords

Suborbital flight $•$ Cell biology $•$ Blue Origin $•$ New Shepard $•$ Sensors $•$ Microgravity

\section{Introduction}

In early 2016, the Department of Applied Aviation Sciences (AAS) at the Embry-Riddle Aeronautical University (ERAU) was granted a suborbital flight opportunity to work on a Science, Technology, Engineering, and Mathematics (STEM) research project. The Spaceflight Operations team in the AAS department was already developing other suborbital payloads as part of the Arete STEM Project (ARETE) to demonstrate joint commercial spaceflight activities. The main aim of this research was to investigate the effect of microgravity on T-cells and to understand how this research could be used to develop T-cell-based therapeutics for cancer patients. A second goal was to monitor the environment that T-cells encountered during suborbital flight. The data recorded will be used to better understand the behavior and functionality of the T-cells when exposed to different stressors. With these aims in mind, this flight opportunity on Blue Origin's New Shepard crew capsule (CC) was originally scheduled at the end of 2016 to early 2017; however, the flight did not occur until December 12, 2017. This suborbital flight was referred to as Mission 7 (M7) aboard the first launch of the New Shepard 3 rocket (or NS3) with a new CC 2.0. There have been three New Shepard vehicles labeled NS1 (single flight), NS2 (five flights), and NS3 (three flights) up to December 31, 2018. This research project was a joint collaboration among scientists at the College of Aviation and the College of Engineering at ERAU, The University of Texas Health Science Center at San Antonio (UTHSCSA), and the Medical University of South Carolina (MUSC), who worked on the preparation of the translational science research project aimed at investigating the effect of microgravity on the T-cells of a murine model.

Suborbital space research is emerging as a popular platform to conduct scientific experiments. It has many advantages compared to researching on the International Space Station, such as cost-effectiveness, rapid turnaround, and an opportunity to validate payloads before investing in more costly space laboratory environments. During the past $5 \mathrm{y}$, we have witnessed the emergence of new private stakeholders, which stiffens the competition for suborbital launches as part of launch-testing technologies and STEM science payloads across several universities. Currently, several companies have reusable vehicles and offer suborbital flights, including Blue Origin's New Shepard and EXOS Aerospace Systems \& Technologies' Suborbital Autonomous Rocket with GuidancE (SARGE) vehicle. Other emerging suborbital research platforms

†Corresponding author: Pedro J. Llanos

E-mail: Ilanosp@erau.edu 

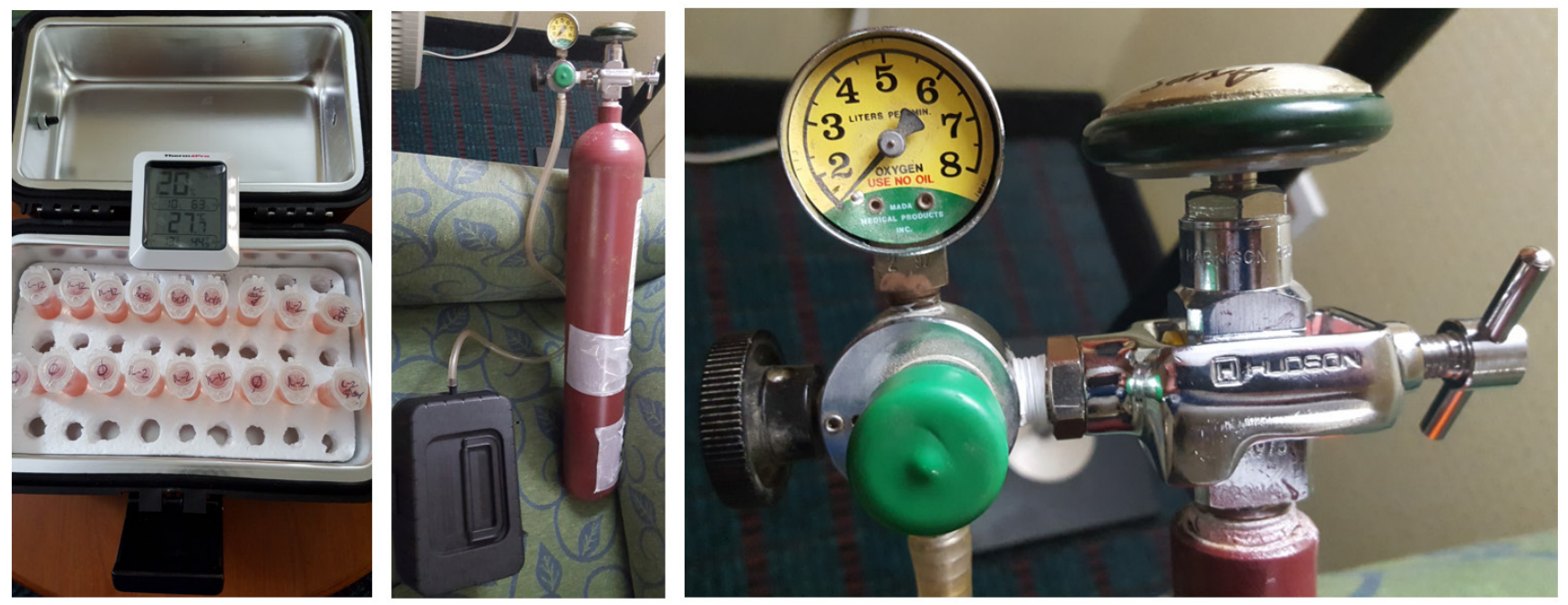

Figure 1. Life support system for T-cells.

include the Virgin Galactic SpaceShipTwo vehicle, American Vector Space Systems' Vector-R vehicle, and New Zealand's Electron launch vehicle, which will be launching suborbital payloads in the near future. Some international companies, such as Europe's first reusable suborbital rocket, PLD Space's Arion 1, which have performed dozens of hot firings of their liquid rocket engine successfully, are planning to conduct test flights in 2019 and to fly new research-oriented science-andtechnology hardware (Llanos et al., 2018).

Although we have been unveiling answers for decades, we are still lacking a comprehensive understanding of the effects of space travel on human physiology (Alwood et al., 2017). There have been many initiatives by the National Aeronautics and Space Administration (NASA) to accelerate this research, such as the release of the Space Biology Plan for 2016-2025, aimed at investigating the biological effects of long-term exposure to space environment (Tomko et al., 2016). Therefore, our scientific findings will build upon current research to expand the knowledge on microgravity effect on T-cells. It will also establish a baseline for us to compare future findings from subsequent suborbital flights aboard various research platforms. In this study, we addressed the various challenges encountered during the preparation of the in vitro biological payload aboard New Shepard from the operational perspective.

\section{Materials And Methods}

The T-cells were processed at the UTHSCSA on December 5,2017 , with the understanding that the launch was going to take place on December 11, 2017. T-cells were transported during a 6-h drive from UTHSCSA to Van Horn (Texas) on
December 8, 2017.

During this time, the T-cells were kept in an incubator at about $34^{\circ} \mathrm{C}-35^{\circ} \mathrm{C}$. The incubator, assembled at UTHSCSA, was a lunch box (Figure 1). While in Van Horn, the T-cells were kept at $28-29^{\circ} \mathrm{C}$ for $3 \mathrm{~d}$. Thus, $8 \mathrm{ft}^{3} / \mathrm{d}$ or $226.53 \mathrm{~L} / \mathrm{d}$ or $9.86 \mathrm{~L} / \mathrm{h}$ or $0.164 \mathrm{~L} / \mathrm{min}$ of gas mixture was required to keep the T-cells in the proper gas environment.

On the L-2 d (December 9, 2017), the team met at the Payload Processing Facility (PPF) at the West Texas Launch Site (WTLS). Here, the T-cells were kept at about $25.5^{\circ} \mathrm{C}$ during the day and at about $28.0^{\circ} \mathrm{C}$ during the night in an electrical heater. The life support system provided enough gas mix for a day instead of $3 \mathrm{~d}$ since the team decided that placing the T-cells in the electrical heater for a controlled temperature environment was more important than having the T-cells in the proper gas mix due to the extreme cold temperatures in Van Horn $\left(-5-0^{\circ} \mathrm{C}\right)$.

On the $L-1 d$ (December 10, 2017), the team estimated the new mass of the payload to be $441 \mathrm{~g}$ (initial mass of NanoLab was $498 \mathrm{~g}$ ), which was less than that anticipated in previous feasibility studies (Vela et al., 2017). This met the mass requirement of $<500 \mathrm{~g}$. NanoRacks provided polycarbonate standoffs placed on the outside of the NanoLab, which is a customer-developed payload package with dimensions of $10.16 \mathrm{~cm} \times 10.16 \mathrm{~cm} \times 20.00 \mathrm{~cm}$ (CubeSat Form Factor; NanoRacks, 2016), to help with flight vibrations. This added an additional $90.4 \mathrm{~g}$. The NanoLab's final weight was $532 \mathrm{~g}$ (including the standoffs).

On December 11, 2017 (intended launch day), the payload was handed off to NanoRacks inside the PPF at 02:45. At 02:40, the New Shepard vehicle was rolled out from the Vehicle Processing Facility. Fifteen minutes later, Blue Origin rolled out the payload from the PPF after being handed off by 


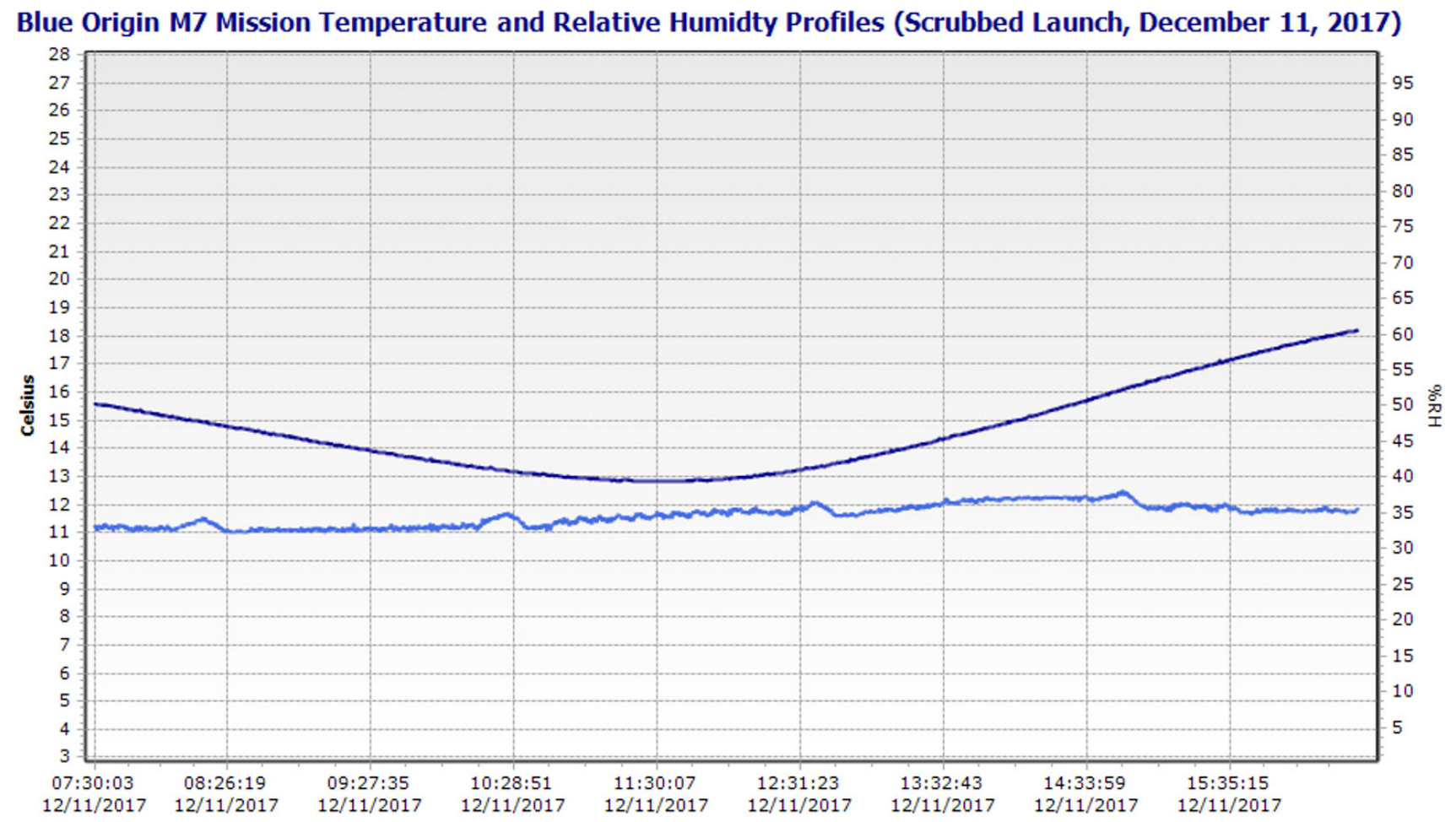

Figure 2. Temperature and relative humidity profiles on the day of the scrubbed Blue Origin launch (December 11, 2017).

NanoRacks. The approximate temperature of the cells was about $26.9^{\circ} \mathrm{C}$ or about $1^{\circ}$ lower than the temperature set in the electrical heater $\left(28^{\circ} \mathrm{C}\right)$. At $03: 35$, the Blue Origin team loaded the payload into the CC. Our sensitive payload sat on the launch pad for about 6-8 h (Lewis, 2017) prior to liftoff. We expect to have later handover times in the near future. Teams were given a few hours of rest before leaving for the viewing site at 08:15. At 08:30, our team was notified that the CC had an internal temperature of $11^{\circ} \mathrm{C}$. Launch was postponed for $1 \mathrm{~h}$ (initial launch time was 11:00). At 09:00, our team was notified that fuel was being loaded into the vehicle, and a weather balloon was released to measure the winds aloft. It was $L-2$ h. At 10:00, our team was notified that liquid oxygen (LOX) was loaded into the vehicle. The team proceeded to the viewing site, and after several short holds at 8 min $30 \mathrm{~s}$ and at $3 \mathrm{~min}$, the launch was scrubbed until the next day. This was announced at 11:15. Our payload was delivered back to the PPF inside the NanoRacks Feather Frame (NFF) at 16:25. The NFF (NanoRacks, 2016) is a self-contained system that receives power from the $\mathrm{CC}$ and provides power and data interface between the NanoLab and Blue Origin's New Shepard payload stack.

At 16:28, NanoRacks handed back the CRExIM payload. It took $20 \mathrm{~min}$ to disassemble the NanoLab. This required removal of the water tape, as well as removal of the lid, foam, tubes, and EDL-XYZ data logger before inspecting the Eppendorf tubes and downloading the data from the data logger.

Temperature at the WTLS was about $4^{\circ} \mathrm{C}$ at the time the vehicle was sitting on the launch pad. Early that morning, the temperature was even lower, around $-2^{\circ} \mathrm{C}$. One of the first actions by the team was to analyze the temperature profile from the data logger (Figure 2) for this scrubbed launch. The highest temperature was $18.23^{\circ} \mathrm{C}$, lowest temperature was $12.80^{\circ} \mathrm{C}$, and average temperature was $14.60^{\circ} \mathrm{C}$. These temperatures are not desirable (too cold) for the T-cells this issue was informed to the Blue Origin team immediately so they could take action for the next launch, which was not confirmed until hours later that day. These were the temperatures measured inside the NanoLab. However, the T-cells were housed in $5.0 \mathrm{~mL}$ Eppendorf tubes and vacuum sealed with Ziploc bags, so the T-cells were probably a few degrees warmer, 3-4 ${ }^{\circ} \mathrm{C}$ warmer as per the team's estimation. This temperature was not quantified. Moreover, the relative humidity ranged from $32.5 \%$ to $37.5 \%$ since the time we handed off the payload at the PPF to the time we retrieved the payload at the PPF from Blue Origin.

M7 was supposed to have launched on December 11, 2017, the last day of the launch window (December 8-11) of 2017. The EDL-XYZ sensor (Marathon Products, 2016a) collected data from 02:29:59 to 16:30:01 (UTC-6:00) Central Time (US and Canada). The set up time was 02:22:16. Data were 
Blue Origin M7 Mission Suborbital Flight Profile (December 12, 2017)

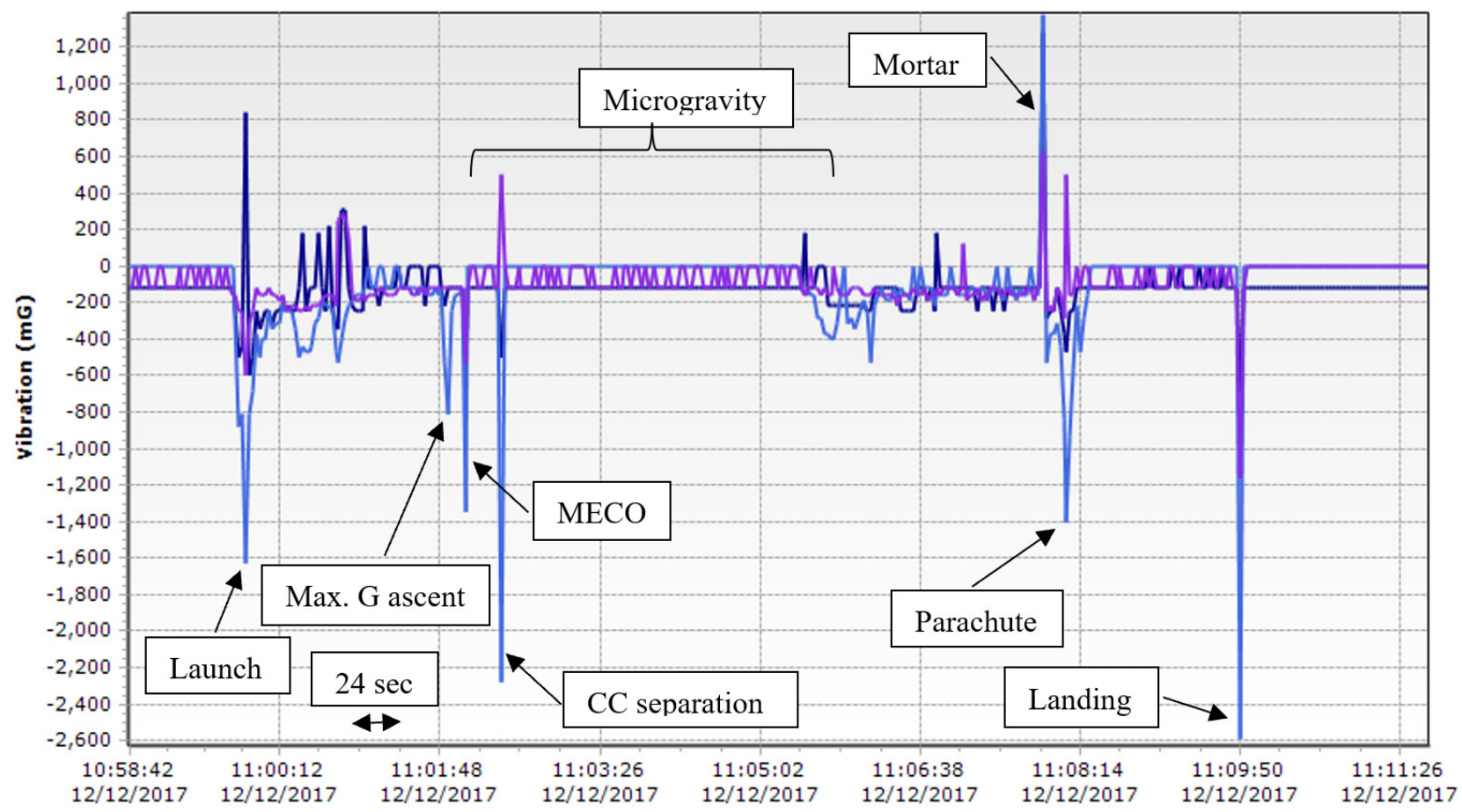

Figure 3. Acceleration profile in each direction (x-dark blue; $y$-light blue; z-purple) during the 10-min suborbital flight. In the $x$-axis (specifying time), there are four minor markers ( $24 \mathrm{~s}$ each) or about $1 \mathrm{~min} 26 \mathrm{~s}$ between two major markers.

then processed using the EDL-XYZ MaxiThermal software (Marathon Products, 2016b).

The next launch opportunity that the teams were given was on December 12, 2017. The team proceeded the same way to prepare the payload again. Given that we ran out of $\mathrm{CO}_{2}$ as the main support system to keep T-cells at their desirable physiological conditions, we used an alternative method to increase their survivability. We used 4-(2-hydroxyethyl)-1piperazineethanesulfonic acid (HEPES) buffer, a zwitterionic organic chemical buffering agent that helps maintain the physiological $\mathrm{pH}$ in cell cultures. HEPES is usually added to media solely for extra buffering capacity when cell cultures require extended periods of manipulation outside of a $\mathrm{CO}_{2}$ incubator. We also replenished the T-cells with fresh cytokines. We achieved this by spinning down the tubes, taking out $2 \mathrm{~mL}$ of the medium and adding fresh complete RPMI medium supplemented with the required cytokines at $1 \times$ concentration. Lastly, we checked the viability of the cells by staining them with Trypan blue dye and observing them under the microscope. To preserve as many cells as possible, we did not take cell suspension from every tube and only performed viability estimates on few conditions. Our results revealed that the T-cells were viable.

On the $L-0$ d (December 12, 2017), the payload was successfully launched from the WTLS into suborbital space.
The sensor data collected data from 03:45:04 to $13: 45: 06$ (Coordinated Universal Time [UTC]-6:00) Central Time (US and Canada). During the data collection process, we programmed the device with a start delay of $5 \mathrm{~h}$. The sensor recorded data (vibration, temperature, and relative humidity) for $9 \mathrm{~h}$, sampling at a rate of $4 \mathrm{~s}$. The team started preparing the payload at 02:15 and it was finalized at 03:50. The vehicle rollout took place at $04: 15$, and the payload was handed off to NanoRacks at 04:45. The launch took place around 11:00 (Figure 3). For comparison, the NanoRacks sensor had a sampling rate of $0.1 \mathrm{~s}$.

While waiting for Blue Origin to bring back the payload to the PPF, we observed the ground control T-cells, which were kept at $27^{\circ} \mathrm{C}$ with Little Hotties hand warmers, which are natural and disposable warmers used by athletes, sportsmen, and skiers. At 15:45, Blue Origin delivered our payload. By 16:00, we inspected the T-cells and the pellet formation and thereafter retrieved the data on acceleration, temperature and relative humidity from the data logger. The highest temperature recorded was $22.43^{\circ} \mathrm{C}$, the lowest temperature was $18.66^{\circ} \mathrm{C}$, and the average temperature was $19.94^{\circ} \mathrm{C}$. During the loading phase, the Blue Origin team wrapped the NFF that housed our payload with a blanket to avoid further exposure to colder temperatures. In this case, the data logger recorded temperatures (Figure 4) more suitable for cell proliferation. It is important to keep 


\section{Blue Origin M7 Mission Temperature and Relative Humidity Profiles (December 12, 2017)}

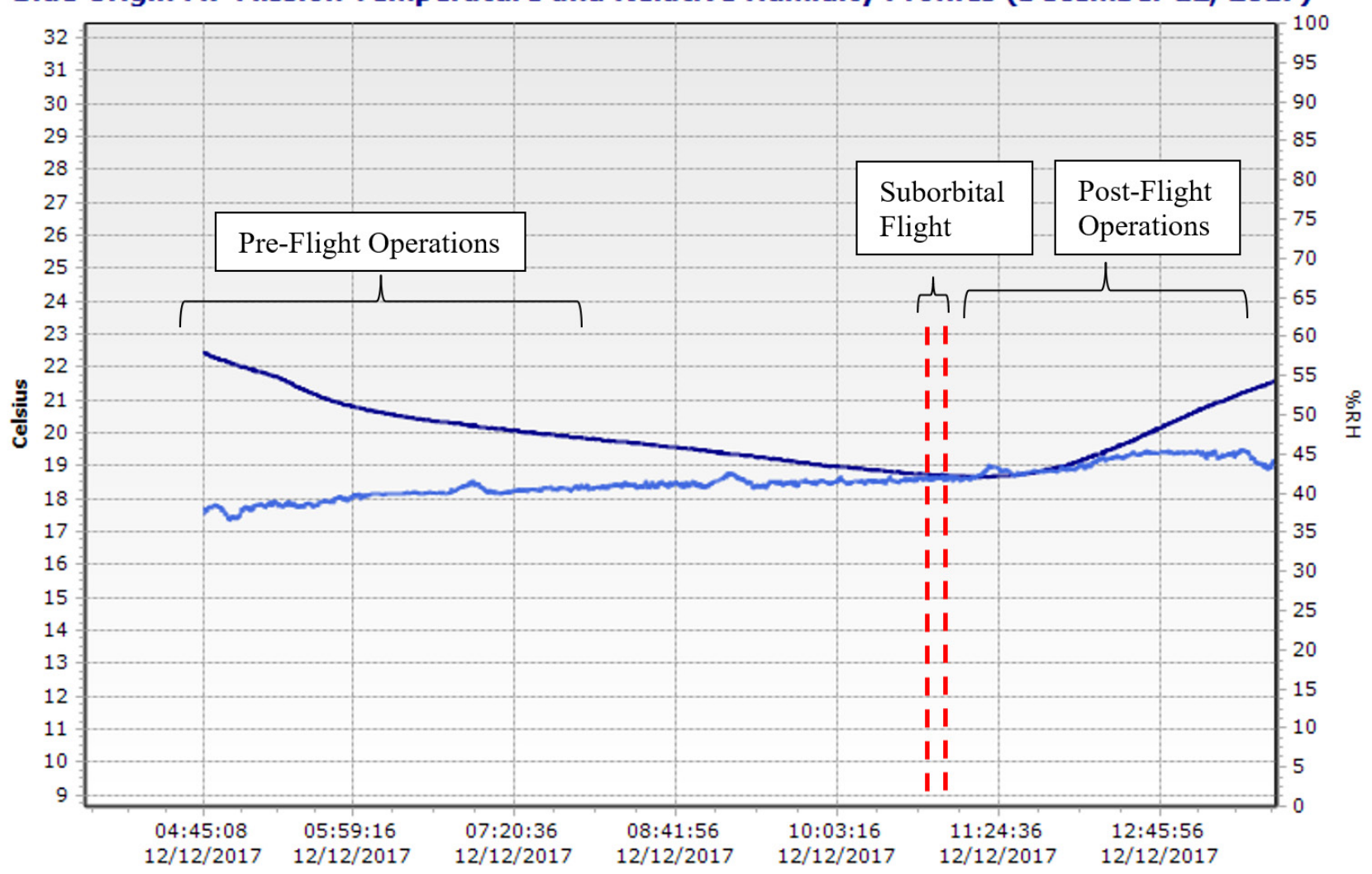

Figure 4. Temperature and relative humidity profiles during the successful Blue Origin suborbital flight.

in mind that the T-cells would have been in slightly warmer temperatures since they were in the foam, vacuum sealed, and inside the tubes. This temperature was not quantified, but as per the team's estimation, it would have been $3-4^{\circ}$ warmer. The relative humidity was between $37 \%$ and $46 \%$.

At 18:30, the team drove back from WTLS to UTHSCSA for immediate analysis of T-cells. The T-cells were immediately placed in a $\mathrm{CO}_{2}$ incubator with $5 \% \mathrm{CO}_{2}$ at $37^{\circ} \mathrm{C}$ around $01: 30$ the next day. After $9 \mathrm{~h}$, the T-cells were assessed for viability, functional integrity, and phenotypic analyses, which will be addressed in a future manuscript by the science team.

\section{Results}

The Blue Origin launch took place on December 12, 2017. The EDL-XYZ sensor collected data from 03:45:04 to 13:45:06 (UTC-6:00) Central Time (US and Canada). During the data collection process, we programmed the device with a start delay of $5 \mathrm{~h}$. The sensor recorded data (vibration, temperature, and relative humidity) for $9 \mathrm{~h}$, recording at a sampling rate of $4 \mathrm{~s}$ with a start delay of $5 \mathrm{~h}$. The number of samples recorded was 8,099 .

\section{Data Extraction and Analysis}

The CRExIM team used the EDL-XYZ sensor and the software by Marathon Products, Inc. (Marathon Products, 2016a) to collect flight data for analysis. In Figure 3 , we provide the acceleration profile depicting all phases of the flight: Launch, MaxG ascent, main engine cutoff (MECO), CC separation, microgravity, mortar drogue deployment, main parachute deployment, and landing.

1. At launch, the magnitude of the acceleration measured by our sensor was about $1.9 \mathrm{G}$.

2. At MECO, the magnitude of the acceleration measured was about $1.4 \mathrm{G}$.

3. At CC separation, the magnitude of the acceleration measured was about $2.4 \mathrm{G}$.

4. Microgravity levels were measured of the order of $120 \mathrm{mG}$, which is of the order of a few milli-Gs, as expected (Lewis, 2017) for about $3.2 \mathrm{~min}$ in all three orthogonal directions. Note that microgravity was present about $20 \mathrm{~s}$ before CC separation, then discontinued very briefly for a few seconds (3-4 s) before microgravity continued without interruption for another $3 \mathrm{~min}$.

5. After the microgravity phase and before deployment of mortar drogues, our sensor measured accelerations 
between $+200 \mathrm{mG}$ and $-50 \mathrm{mG}$ in the $x$-direction, between $0 \mathrm{mG}$ and $-500 \mathrm{mG}$ in the $y$-direction (flight direction), and between $+130 \mathrm{mG}$ and $-250 \mathrm{mG}$ in the z-direction for about 2.4 min.

6. During mortar drogue deployment, the magnitude of the acceleration was near $2 \mathrm{G}$. This was a transient event.

7. During parachute deployment, the magnitude of the acceleration measured was about $1.55 \mathrm{G}$.

8. During landing, the magnitude of the acceleration measured was near $3 \mathrm{G}$.

NanoRacks also provided their data during the day of the scrubbed launch and the actual flight on the launch day. We are planning to compare our sensor data with the NanoRacks data. The NanoRacks team observed an approximate amoun of $2 \%$ duplicate packets in the data and a $0.3 \%$ dropped packet count as provided by the NanoRacks team to maximize the data collection for the next mission. The data observed in Figure 5 were provided by Blue Origin at $100 \mathrm{~Hz}$ and shows evidence of some very short shock events at CC separation (Figure 5d), drogue chute deployment (Figure 5g), and main chute deployment (Figure $5 \mathrm{~h}$ ). These pulses are only a single data point wide, suggesting pulse durations $<100 \mathrm{~ms}$. These pulses were the result of the reaction control system when firing their thrusters right after capsule separation (McPherson et al., 2017). Sustained acceleration peaks can be observed during ascent at about $2.9 \mathrm{G}$ and during reentry at $4.9 \mathrm{G}$.

The CC spent $3.15 \mathrm{~min}$ in microgravity $(0.01 \mathrm{~g}$ to about $0.05 \mathrm{~g}$ ) during the coast period from about $172,052 \mathrm{ft}$ during the ascent path up to about 193,125 ft during the descent path. These are the lowest levels of microgravity that the $\mathrm{CC}$ experienced. However, slightly higher levels of microgravity were also sensed by the $\mathrm{CC}$ after its separation and during the descent past apogee. The maximum apogee height reached by the New Shepard vehicle was $322,440.3125 \mathrm{ft}$ or $98.280 \mathrm{~km}$ (Figure 5). Blue Origin's sensors provided the following readings:

1. The maximum $\mathrm{G}$ on ascent was $2.910 \mathrm{~g}$ at $134,590 \mathrm{ft}$ and $121.08 \mathrm{~s}$.

2. MECO occurred at $170,513 \mathrm{ft}$ and $132.66 \mathrm{~s}$.

3. CC separation occurred at $233,167 \mathrm{ft}$ and $155.6 \mathrm{~s}$, with Mach number of 3.62 .

4. The maximum $\mathrm{G}$ on reentry was $4.959 \mathrm{~g}$ at $74,887 \mathrm{ft}$ for about $361.26 \mathrm{~s}$

5. Mortar deploy drogues occurred at $6,469.6 \mathrm{ft}$ and $481.09 \mathrm{~s}$. The CC sensed an acceleration of $9.185 \mathrm{~g}$.

6. Peak parachute load happened at $3,042.5 \mathrm{ft}$ at $496.7 \mathrm{~s}$, with Mach number of 3.15.

7. Landing impact can be observed as the CC touches ground of the WTLS for about $1 \mathrm{~s}$ from $598.8 \mathrm{~s}$ to about $599.8 \mathrm{~s}$. Several small bumps in the acceleration profile can be observed, which may represent short-duration impacts.
During the 10- to 11-min suborbital flight duration, we expected sustained accelerations of $4-4.9 \mathrm{G}$ for about $15 \mathrm{~s}$. Sustained accelerations of 2.5-3 G were observed for about $15 \mathrm{~s}$. About $68 \%$ of suborbital flight accelerations fall under $1 \mathrm{G}, 16 \%$ between $1 \mathrm{G}$ and $2 \mathrm{G}$, and about $16 \%$ above $3 \mathrm{G}$. However, accelerations in our science payload were at least $25 \%$ smaller than the above-expected accelerations.

Note that these accelerations measured by our sensor housed inside the NanoLab (Figure $6 b$ ) are similar to the theoretical simulations provided by Blue Origin (Blue Origin, 2017 ) in the New Shepard Payload User's Guide (Figure 7c). Our NanoLab was placed inside the NFF with the following orientation: $x$-direction pointing in the horizontal direction, $y$-direction pointing upward (aligned to the vertical flight direction of the New Shepard vehicle), and z-direction being perpendicular to the $x$ - and $y$-directions (Figures 6a and 6b). Figure $6 \mathrm{c}$ depicts the acceleration map logged by the Blue Origin sensor during the suborbital flight on December 12, 2017. This three-dimensional plot helps visualize the contour patterns during acceleration of the suborbital flight with the vertical axis being the altitude, the horizontal axis being the mission elapsed time, and the third dimension being the colormapped acceleration values (Figure 6c).

The dotted dashed lines in Figure 6 at $132.6 \mathrm{~s}$ and $155.6 \mathrm{~s}$ indicate the MECO and CC separation phases of the New Shepard, respectively. The dotted line at $361.3 \mathrm{~s}$ indicates the maximum acceleration experienced by the New Shepard. Finally, the dashed lines at $481 \mathrm{~s}$ and $496 \mathrm{~s}$ represent the mortar drogues and the main parachutes being deployed, respectively. The intent of Figure 7 was to show a graphical comparison between the accelerations (Figure 7b) sensed by the NFF sensor and the simulated values (Figure 7c), while Figure $7 \mathrm{a}$ illustrates the accelerations sensed by this sensor as a function of both altitude and time. As observed, both sensed and simulated accelerations show very similar acceleration profiles, although the acceleration sensed by the NFF sensor shows more frequent oscillations during the suborbital flight.

After the CC and the New Shepard booster landed, the team relocated from the site location near the Mission Control Center to the landing locations. It took about $1 \mathrm{~h}$ after landing before we arrived at the CC landing location (Figure 9). At that time, the Blue Origin team was already conducting postlanding recovery operations, such as recovery of its three parachutes. The university teams stayed in this area for about $30 \mathrm{~min}$ before they were relocated to the booster location. The New Shepard booster and the CC landed about $2 \mathrm{mi}$ northwest and northeast, respectively, from the launch pad, each landing about $1 \mathrm{mi}$ from each other, proving a very welldefined flight transition corridor.

Figure 10 illustrates the launch pad at the WTLS. The velocity (east) during the microgravity phase is depicted in Figure 11. 


\section{Blue Origin M7 Mission Suborbital}

Flight (December 12, 2017)

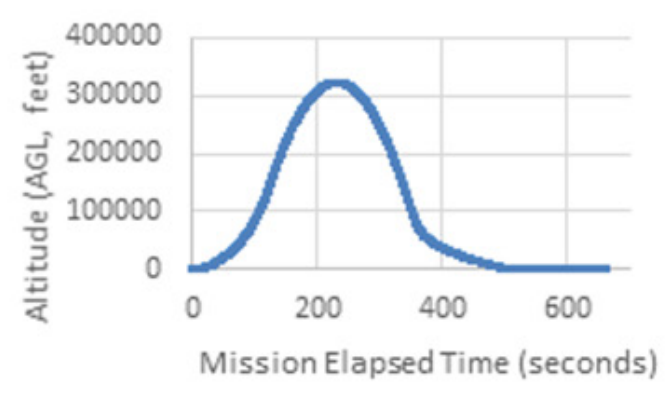

a.

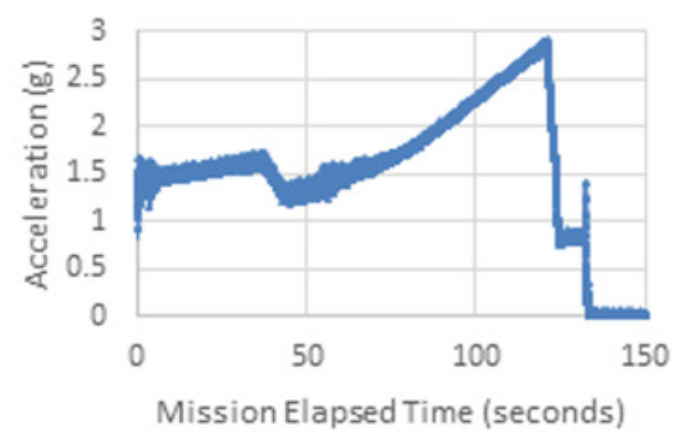

c.

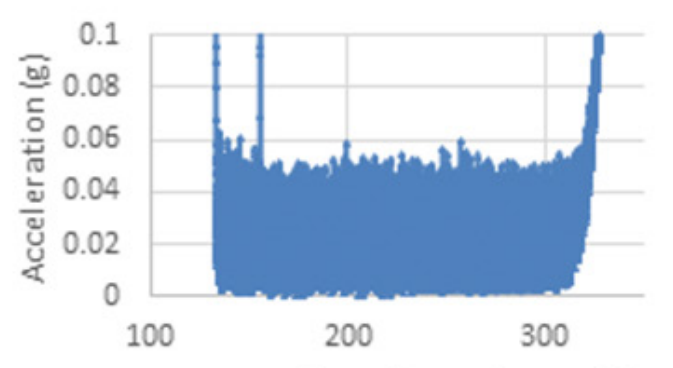

Mission Elapsed Time (seconds)

e.

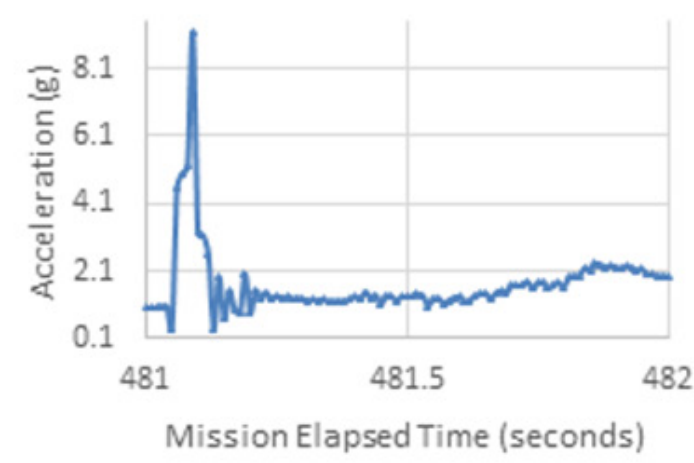

g.
Blue Origin New Shepard's Crew Capsule Acceleration Profile (December 12, 2017)

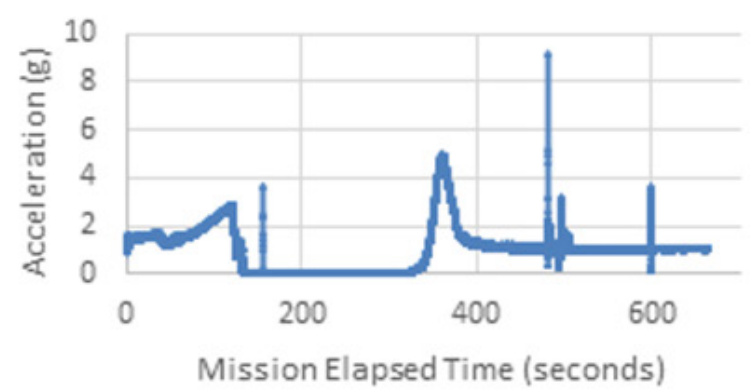

b.

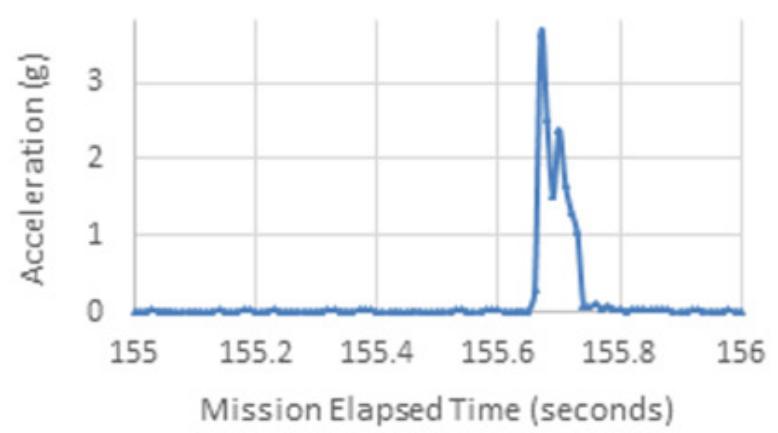

d.

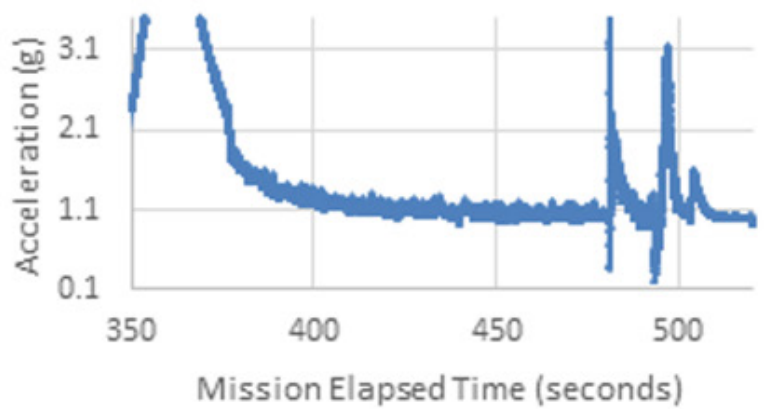

f.

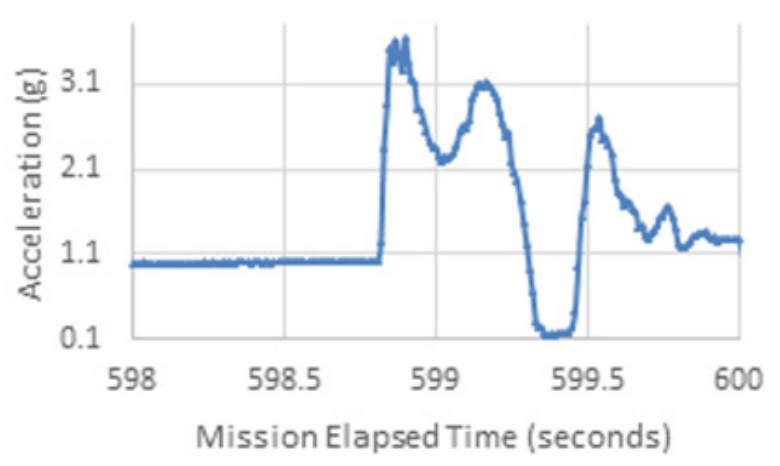

h.

Figure 5. a. Blue Origin suborbital flight profile. b. New Shepard's full acceleration profile. c. Acceleration at maximum G on ascent, and the MECO phases. d. CC separation. e. Microgravity phase. f. Reentry phase. g. Peak parachute load. h. Landing impact. 

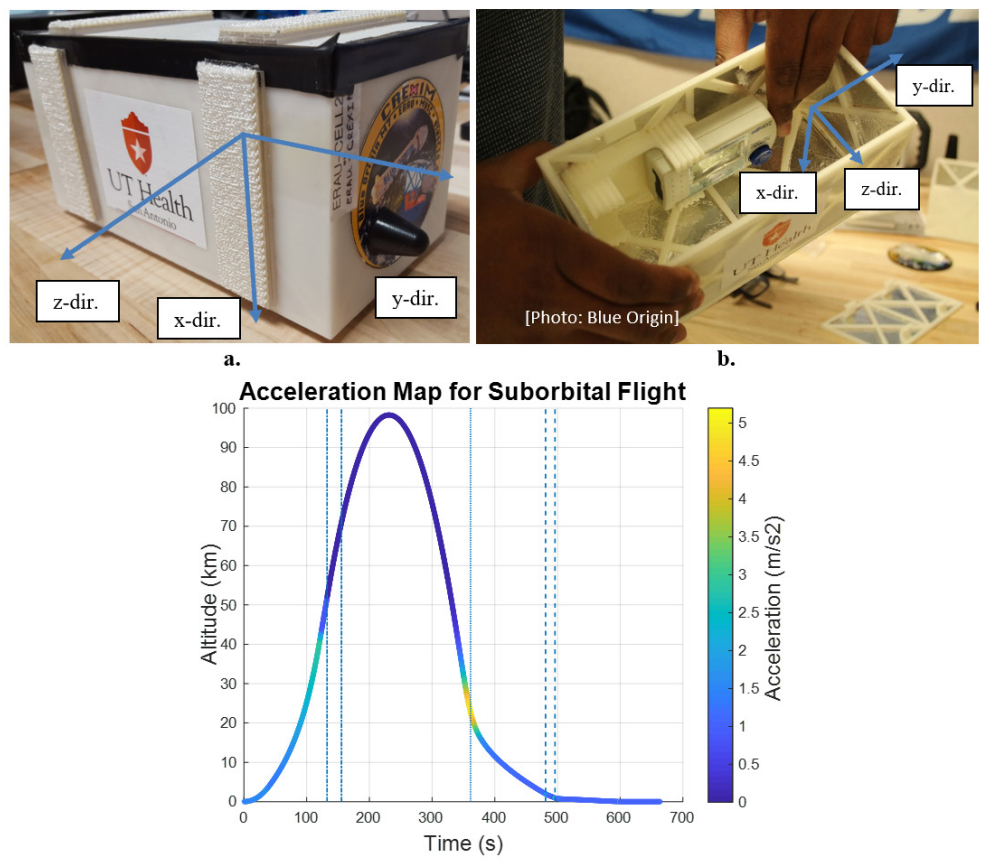

Figure 6. a: Enclosed NanoLab ready to being handed off to NanoRacks. b: Student conducting an integration test for the sensor inside the NanoLab at the PPF before flight. c. Acceleration contour map during suborbital flight on December 12, 2017. Right vertical column indicates the variation of acceleration as a function of altitude and time.
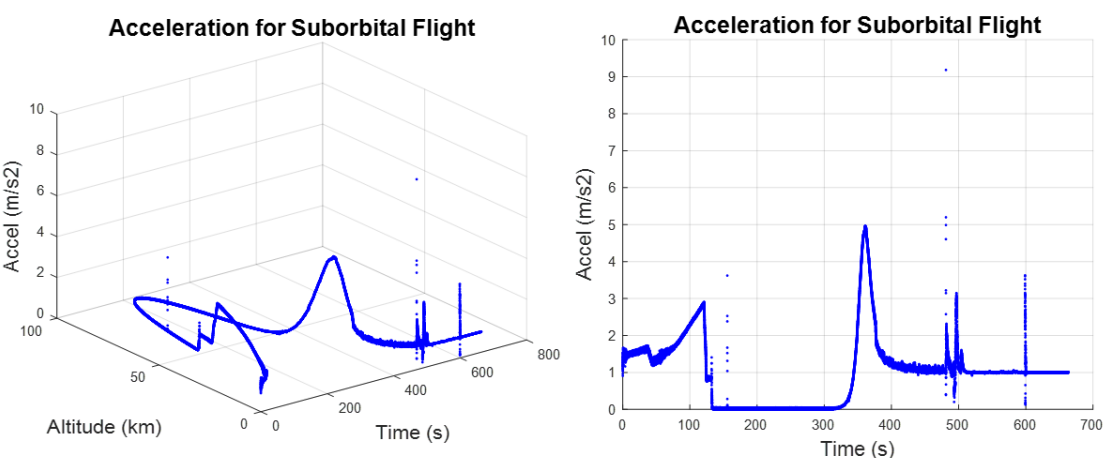

a.

b.

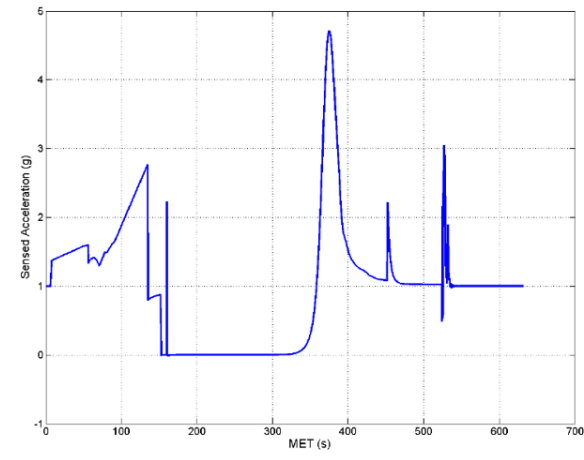

Figure 7. Blue Origin acceleration profile. a: 3D plot of acceleration sensed, altitude, and time. b: Acceleration sensed by NFF sensor as a function of time: acceleration as a function of time as in the Payload User's Guide (PUG). 


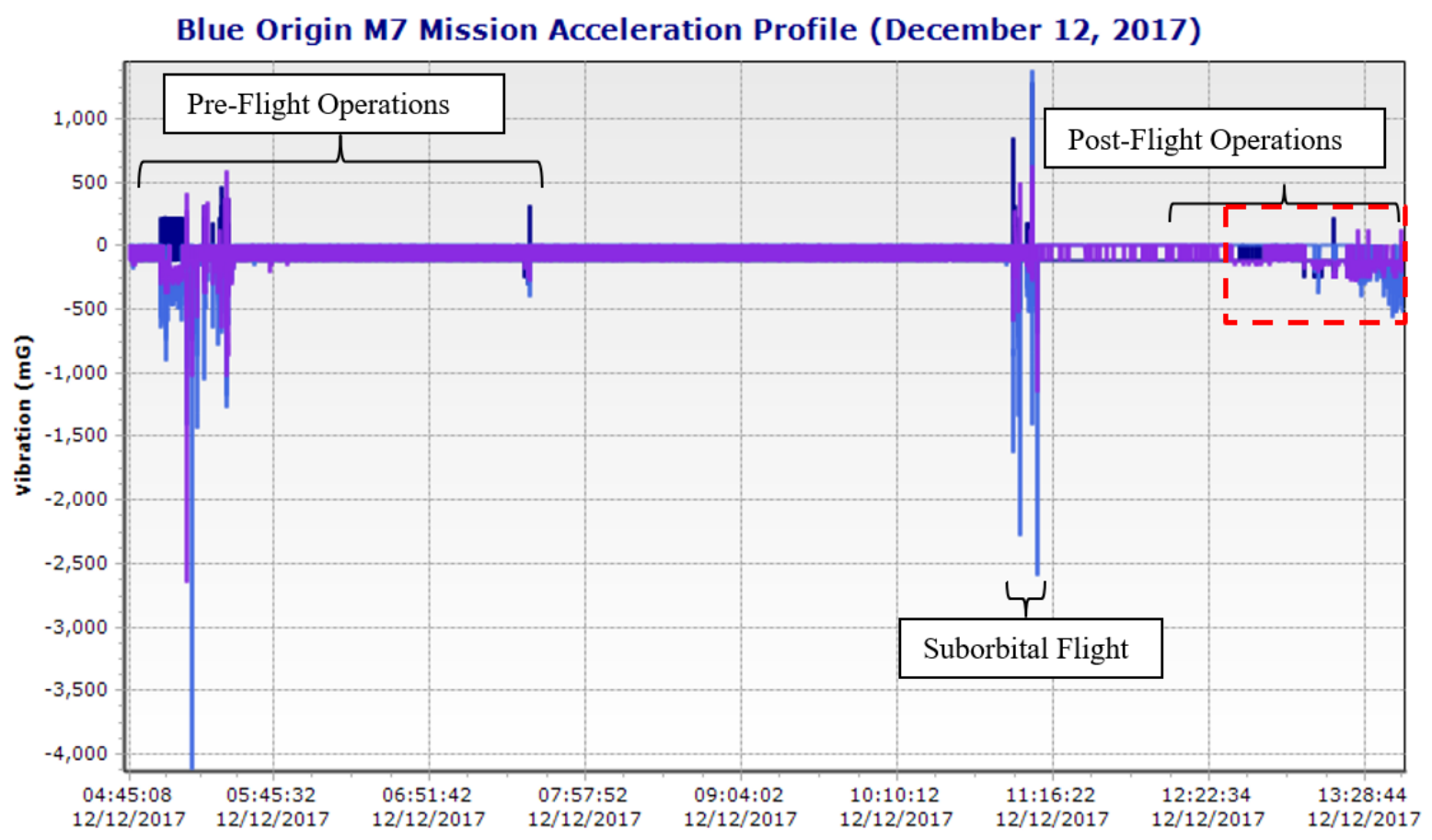

Figure 8. Overview of the sequence of events from preflight operations to postflight operations. Dashed red box shows the blowout section depicted in Figure 9.

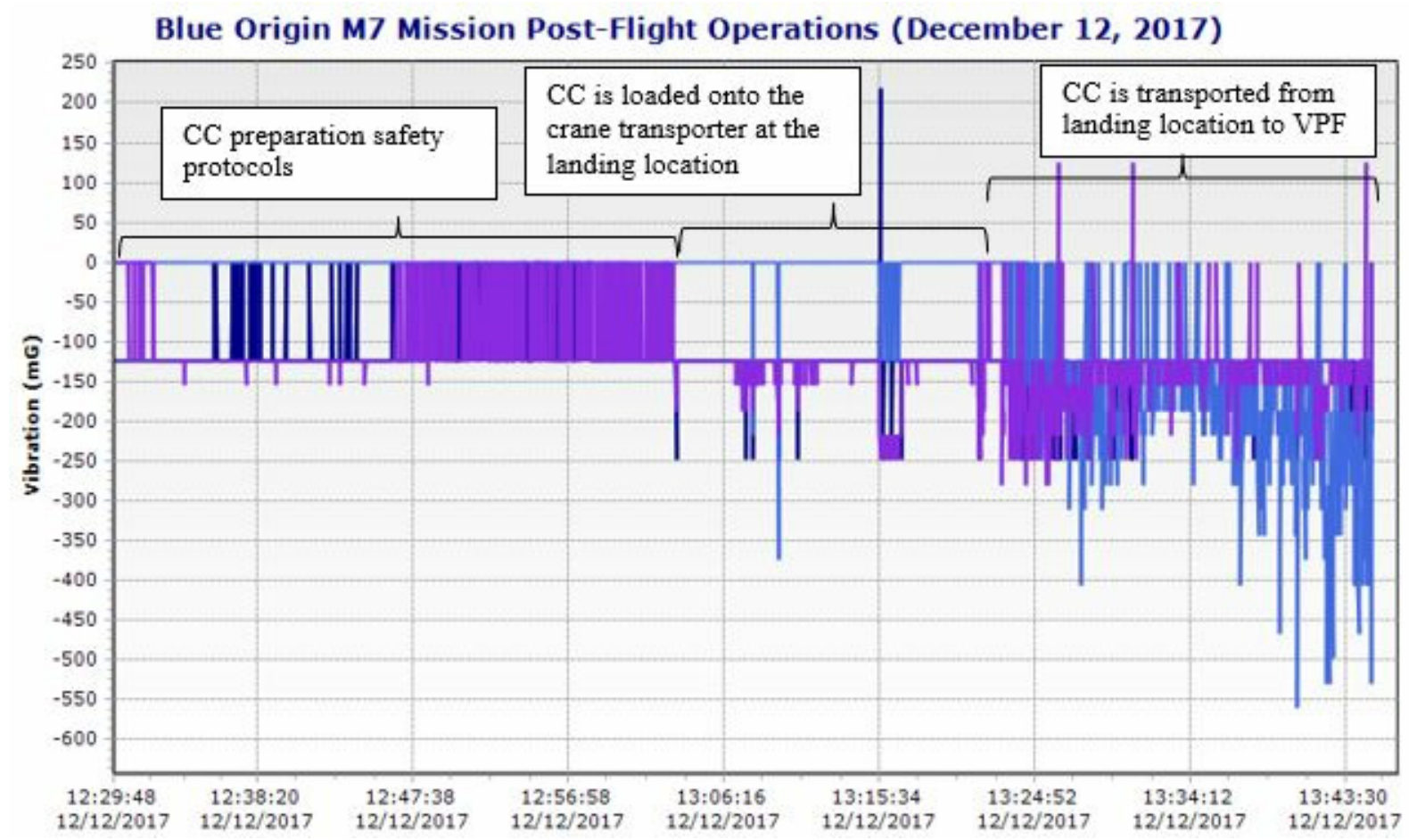

Figure 9. Estimated sequence of events for the postflight operations is a zoomed section of Figure 8 as represented by the dashed red box. 
A

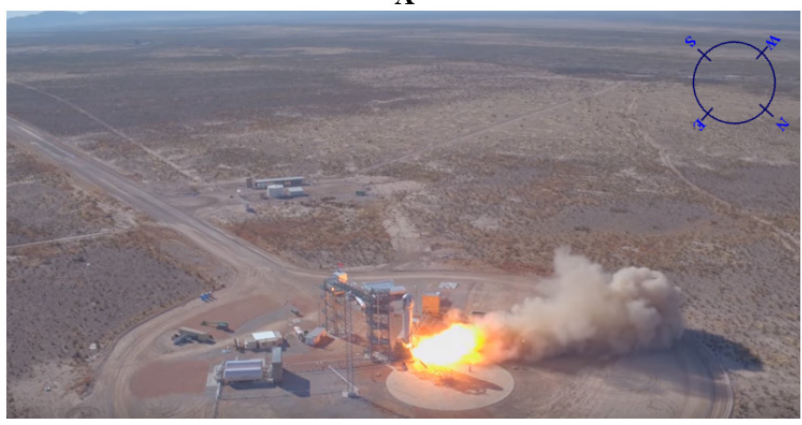

B

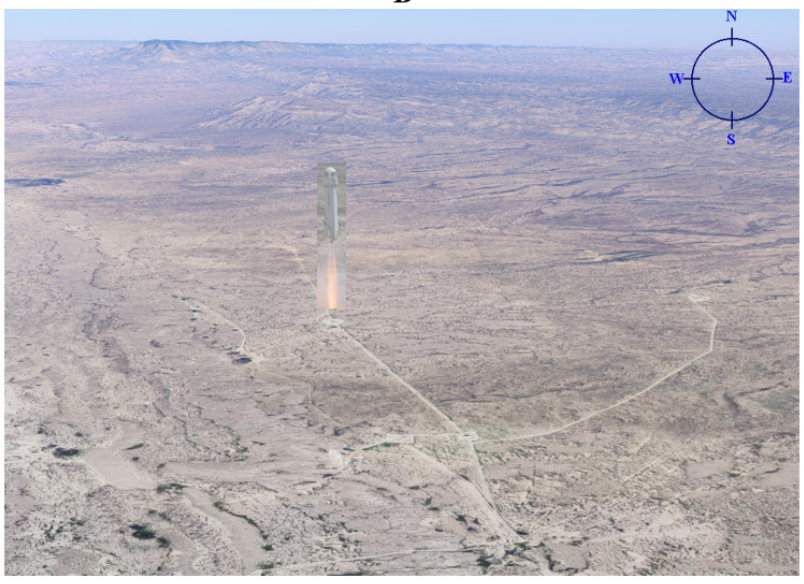

Figure 10. a. New Shepard M7 mission taking off from the WTLS (www.blueorigin.com) showing the orientation of the launch site. b. Wider view of the West Texas Launch Site (Google Maps).

The equation in Figure 11 could be utilized to predict the east velocity at any time during this phase of approximately $3.2 \mathrm{~min}$. The blue line represents the data points, and the red dashed line represents the polynomial fit with a correlation factor of 0.999 .

The velocity (vertical) in feet per second during the microgravity phase can be approximated by a linear fit between $144 \mathrm{~s}$ and $344 \mathrm{~s}: V_{\text {vert }}=-(31.033)^{*}$ time $+7,183.3$. The velocity (north) ranged between $27.40 \mathrm{ft} / \mathrm{s}$ to $19.87 \mathrm{ft} / \mathrm{s}$ during the microgravity phase (Figure 12). During the first $2.5 \mathrm{~min}$ of microgravity, the velocity (north) ranged from $27.4 \mathrm{ft} / \mathrm{s}$ to about $27 \mathrm{ft} / \mathrm{s}$. The red dashed line represents the polynomial fit during this segment with a correlation factor of $R=0.989$, which indicates a good fit. It is worth to note a small rapid variation in the velocity (north) at $155.6 \mathrm{~s}$ from $27.15 \mathrm{ft} / \mathrm{s}$ to about $27.4 \mathrm{ft} / \mathrm{s}$, which is due to the CC separation event. T-cells are usually are in a motile phase during which they scan surfaces of other cells, so that they could engage T-cell receptors and elicit immunological responses (Krummel et al., 2014). Various stimuli could increase T-cell motility and change their morphology. For example, our group has observed different shape formations of T-cells exposed to clinorotation versus $1 \mathrm{~g}$ (unpublished data). Given that T-cell motility is influenced by its environment (Krummel et al., 2016), it is likely that T-cell motility may be affected by the velocity of the CC. Higher velocity may limit the ability of T-cells to effectively detect their targets, as they become less intensive in scanning surfaces of other cells, whereas a slower velocity could lead to scanning a larger area. Our T-cells were exposed to about $3.5 \mathrm{~min}$ of microgravity. During this time, the cells may have been distributed differentially in the tube, depending on their adherence to the surface of the Eppendorf tube, and may have obtained various (unquantified) source of nutrients from the media.

Therefore, it is important to record velocity data, so that these could be used in conjugation with scientific data to better interpret T-cell behavior. Thus, given that each suborbital mission has different velocity profiles, it is extremely important to record these data for comparison purposes across different experiments as our team is flying another science payload in the near future.

\section{Discussion}

Our team successfully completed the first Blue Origin/ NanoRacks deliverable, namely, the Payload Data Package (PDP) submittal, on June 16, 2017. The second deliverable was the Payload Safety Package (PSP) submission, which was fulfilled on February 27, 2017. Each deliverable was followed by a pertinent review 2 wk after submission. The third deliverable was the Launch Site Integration Package (LSIP), which is normally due 1 mo prior to launch. Initially, our launch was scheduled for early Q4 2017 and our team successfully submitted the LSIP on October 1, 2017, with an expected launch on November 3, 2017. The launch was pushed back again to November 14, 2017. Further launch vehicle-testing operations were required by the Blue Origin team, taking the launch to December 8, 2017, with a launch window from December 8 to December 11, 2017. On November 26, 2017, the CRExIM team was notified of a change in the launch date to December 11, 2017. This final launch date was given the day of the scrubbed flight, which the team came to know about 3 min before liftoff. Finally, our payload needed to be rearranged to maximize the science collected on December 12, 2017. Had this launch been scrubbed again, it would have left our team with no science data since the in vitro experiment would have reached an apoptosis stage. Not having the proper resources in the PPF made the team conduct all the experiments in a hotel environment. This was one of the most critical aspects of the mission that perhaps affected the functionality of the T-cells. Future recommendations are to have access to a clean room 


\section{Velocity (East) for New Shepard's M7 during Microgravity Phase}

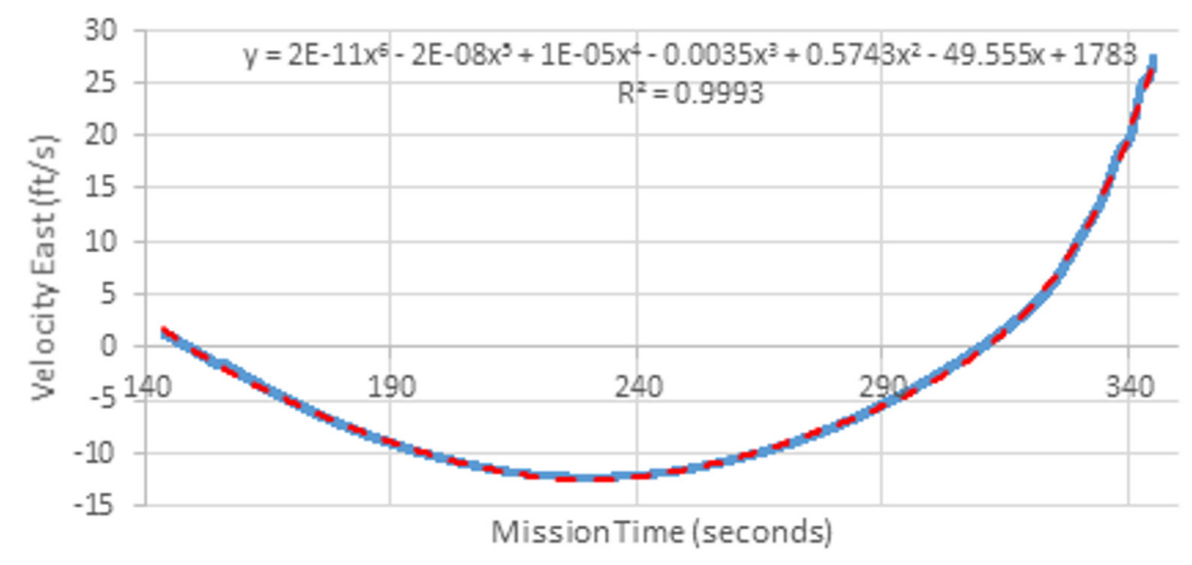

Figure 11. Velocity (east) during the microgravity phase of the New Shepard's crew capsule.

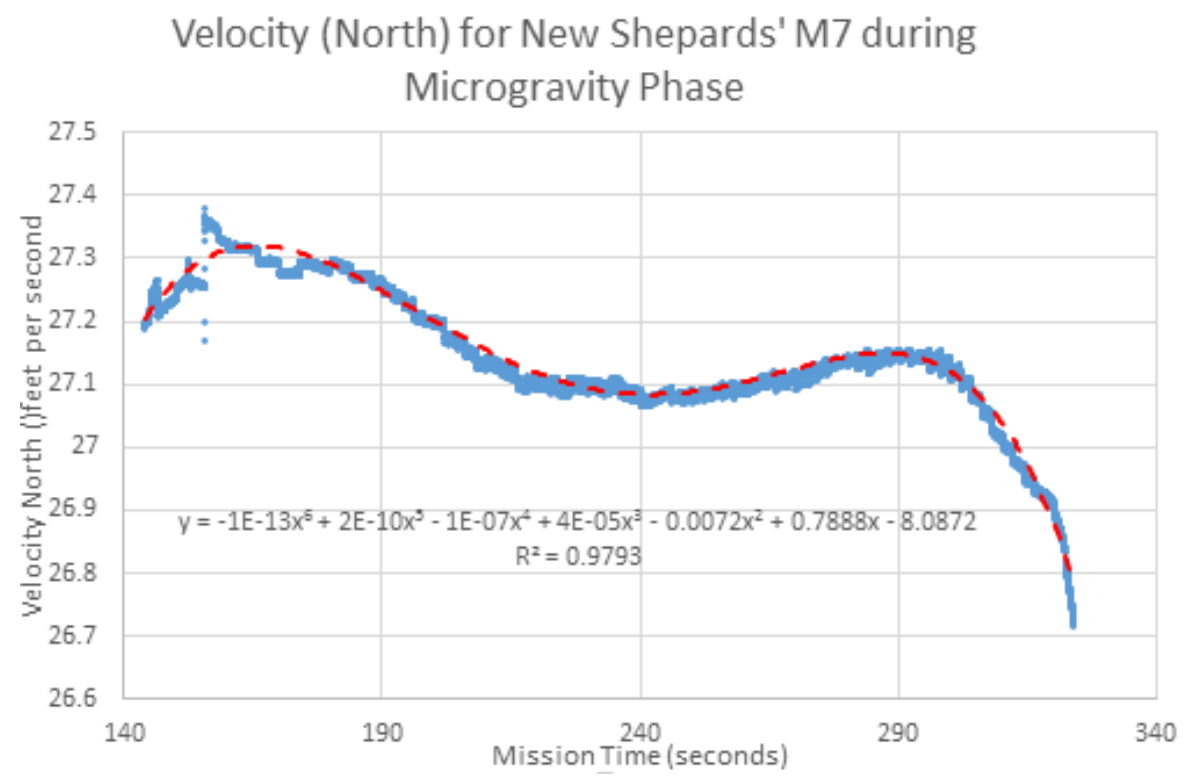

Figure 12. Velocity (north) during the microgravity phase of the New Shepard's crew capsule.

with a sterile hood to conduct the biological experiments in case of any mission delays, as well as to have more refined and consistent procedures at the PPF should the mission be scrubbed again. As for the data collected by our sensor, our team is already working on having a new data logger with a more refined sampling rate that will match the one from the NFF sensors, and which will be flown on the next suborbital launch. Since the NFF's sensors and our sensor were placed in different locations, in the future, hopefully, NanoRacks may provide us with the actual coordinates of our NanoLab so that we can better correlate our findings.
Our unpublished preliminary results suggest that suborbital space flight modulated the expression of certain subpopulations of T-cells, especially cluster of differentiation (CD) $4+$ and CD8+ cells. Moreover, we have also observed functional differences between the flown T-cells and the ground controls. Our scientific experiments and data analyses were conducted at Dr. Wargovich's laboratory at the UTHSCSA using the flow cytometry core facility. In addition, we have performed a complex cytokine expression analysis using the Invitrogen Mouse Custom ProcartaPlex 5-plex. All scientific data are currently being incorporated in a manuscript, which will be 
published in the spring of 2019. The impact of this research is to expand our understanding of T-cell behavior and functional capacity under microgravity conditions, so that we can develop new targets for immunotherapeutic strategies for astronauts during long-term space missions. Our long-term objective is to continue collaborative research across multiple disciplines with various research and academic institutions; by working together, we can reduce some of the research science gaps to enhance our understanding of prospective space science activities.

\section{Acknowledgments}

This work was partially supported by the Department of Applied Aviation Sciences at Embry-Riddle Aeronautical University and by funds awarded from the Faculty Innovative Research Science and Technology (FIRST) program, which allowed our team to purchase the Invitrogen Mouse Custom ProcartaPlex 5-plex to conduct part of the cell analysis during the Pl's visit to UTHSCSA research facilities. The authors would like to thank the Faculty Research Development Program (FRDP) at ERAU. We would like to acknowledge the Applied Aviation Sciences Payload and Integration Laboratory in the College of Aviation and the Structures Laboratory in the College of Engineering. In addition, we would like to thank Dr. Mike Wargovich's laboratory at the UTHSCSA for providing laboratory space and resources to conduct our experiments.

\section{References}

Alwood JS, Ronca AE, Mains RC, Shelhamer MJ, Smith JD, Goodwin TJ (2017) From the bench to exploration medicine: NASA life sciences translational research for human exploration and habitation missions. NPJ Microgravity 3, 5.

Blue Origin (2017) New Shepard Payload User's Guide For Research and Education Missions. NSPM-MA0002-C Rev C. Available at: https://www.blueorigin.com/ (Accessed April 25, 2019)

Krummel MF, Bartumeus F, Gérard A (2016) T cell migration, search strategies and mechanisms. Nature Reviews Immunology 16, 193-201.

Krummel MF, Friedman RS, Jacobelli J (2014) Modes and mechanisms of T cell motility: roles for confinement and Myosin-IIA. Current Opinion in Cell Biology 30, 9-16.

Lewis B (2017) Suborbital Payload Spaceflight Aboard Blue Origin's New Shepard Vehicle. Next- Generation Suborbital Researchers Conference, 18-20 December 2017.

Llanos JP, Andrijauskaite K, Rubinstein PM, Chan LS (2018) Investigation of zebrafish larvae behavior as precursor for suborbital flights: feasibility study. Gravitational and Space Research 6(1), 37-57.
Marathon Products (2016a) edl-XYZ Data Logger, San Leandro, CA: Marathon Products.

Marathon Products (2016b) Maxi-Thermal Software, San Leandro, CA: Marathon Products.

McPherson K, Kelly E, Keller J, Ibrahim A, Wagner E, Hrovat K (2017) analysis of vibratory data collected by the space acceleration measurement system (SAMS) on blue origin, June 19, 2016. Gravitational and Space Research 5 (2).

NanoRacks (2016) NanoRacks Feather Frame (NRFF) Payload User's Guide (PUG), released 2016.11.15.

Tomko D, Souza K, Smith J, Mains R, Sato K, Levine H, Quincy C, Mills A, Zeituni A (2016) NASA space biology science plan 20162025. Available at https://www.nasa.gov/sites/default/files/atoms/ files/16-03-23_sb_plan.pdf (Accessed April 25, 2019)

Vela AJ, Lindsquist R, Andrijauskaite K, Llanos JP (2017) Operations and Testing of a Suborbital Research Payload. AIAA SPACE and Astronautics Forum and Exposition, September 12-14, Orlando, FL. 